\title{
ESTADO, SOBERANÍA Y CONSTITUCIÓN: ALGUNOS \\ RETOS DEL DERECHO CONSTITUCIONAL ANTE EL SIGLO XXI
}

\author{
GURUTZ JÁUREGUI \\ Catedrático de Derecho Constitucional \\ Universidad del País Vasco
}





\section{ESTADO, SOBERANÍA Y CONSTITUCIÓN: ALGUNOS RETOS DEL DERECHO CONSTITUCIONAL ANTE EL SIGLO XXI'}

POR

GURUTZ JÁUREGUI

Catedrático de Derecho Constitucional

Universidad del País Vasco

\section{INTRODUCCIÓN}

Los veinte años transcurridos desde la aprobación de la Constitución de 1978 constituyen, sin lugar a dudas, el período más fértil y positivo de toda la historia constitucional española en lo que al desarrollo y fortalecimiento del Estado democrático de Derecho se refiere. A lo largo de estos veinte años se ha consolidado de manera definitiva

1 Este trabajo ha sido posible gracias a una ayuda financiera obtenida del Gobierno Vasco / Eusko Jaurlaritza (Proyecto de Investigación GV PI 97/67). Agradezco al profesor Alejandro Saiz Arnaiz las numerosas sugerencias e indicaciones realizadas al contenido del mismo. En otro orden de cosas, cuando ya se encontraba en imprenta este artículo ha aparecido un interesante trabajo de Pedro de Vega en el que se abordan en buena medida los mismos problemas objeto de mi análisis, aunque desde una perspectiva y con un enfoque diferentes. Vid. Pedro DE VEGA, "Mundialización y Derecho Constitucional: la crisis del principio democrático en el constitucionalismo actual», en Revista de Estudios Políticos, n. ${ }^{\circ} 100$, Madrid, abril/ junio 1998, pp. 13-56. 
el respeto y la valoración del Derecho como instrumento de convivencia y regulación de las relaciones sociales entre los ciudadanos. La configuración de la Constitución como norma jurídica fundamental ha hecho posible que sus mandatos queden fuera de la disponibilidad tanto de los ciudadanos como, sobre todo, de los poderes públicos. La sujeción de los ciudadanos y de los poderes públicos a la Constitución y al resto del ordenamiento jurídico ha supuesto el establecimiento de unos límites que nadie puede ni debe franquear, sean cuales fueren los motivos, los fines o las razones que induzcan a ello.

El carácter novedoso de la configuración de España como Estado constitucional y la consolidación del correspondiente sistema democrático provocó inicialmente, un extraño, aunque en cierto modo comprensible, desenfoque (algo asi como esa visión óptica producida cuando introducimos un cuerpo sólido alargado en un recipiente de agua) del concepto de la Constitución y el Derecho Constitucional con respecto a la visión mantenida en otros paises de nuestro entorno. Me explico. Mientras en esos países se abordaban los problemas derivados de una eventual crisis de la concepción clásica del Estado y la función del Derecho en general y la Constitución en particular ante esa crisis, en España prevalecía una cierta sacralización del Estado, y se teorizaba sobre las correspondientes virtudes taumatúrgicas del Derecho, y de la Constitución como instrumento racionalizador de aquél.

En los últimos años se ha producido, sin embargo, una progresiva evolución que nos ha permitido despertar - a veces de forma bastante brusca y abrupta - de ese particular nirvana jurídico-constitucional en el que nos hallábamos inmersos. Dicho de otra forma, parece que, por fin, nuestra homologación con el resto del mundo democrático resulta ya definitiva. Ello implica la necesidad de plantearnos con toda crudeza la situación de crisis (entendiendo el concepto de crisis como un proceso de cambio en el que al diagnóstico de los vicios presentes, a la certeza de las estructuras e instituciones viejas se opone la incertidumbre de lo desconocido y de las alternativas futuras) en la que nos hallamos inmersos, y en lo que aquí concierne, el papel de la Constitución y el constitucionalismo frente a la misma.

Toda Constitución es Constitución en el tiempoz: la realidad social, a la que van referidas las normas, está sometida al cambio histórico y éste, en ningún caso deja incólume el contenido de la Constitu-

2 Konrad HeSSE, "Constitución y Derecho Constitucional», en AA.VV., Manual de Derecho Constitucional, IVAP-Marcial Pons, 1996, p. 9. 
ción. Por ello, la Constitución y el Derecho Constitucional deben estar atentos al devenir de los acontecimientos, deben cobrar conciencia del significado de los nuevos problemas para los derechos fundamentales y para los órganos estatales establecidos por la Constitución, de las tareas y formas de llevarlas a cabo, del establecimiento de nuevas disposiciones, instituciones, etc...

Esta tarea resulta particularmente urgente en el caso del Derecho Constitucional dado el abismal desfase producido en los últimos años entre la realidad social y las instituciones, entre la normalidad y la normatividad constitucionales. Este desfase ha supuesto que mientras la realidad social, política, económica, cultural, tecnológica, etc... se apresta con decisión a afrontar los retos del siglo XXI, las vigentes Constituciones siguen ancladas en esquemas decimonónicos o, en el mejor de los casos, en un sistema institucional diseñado en el primer tercio de este siglo para un mundo y unas realidades que poco o nada tienen que ver con el momento actual. En el momento actual, las Constituciones se enfrentan a un doble reto. De una parte deben actualizar y profundizar el contenido de sus fines y valores, adecuándolos a los valores sociales, éticos y culturales vigentes. De la otra, deben llevar a cabo una profunda transformación de las bases institucionales en las que se asientan los vigentes sistemas democráticos.

La efemérides del vigésimo aniversario de nuestra Constitución supone una excelente oportunidad para reflexionar sobre algunos de los retos que se le presentan a la Constitución y al Derecho Constitucional en este apasionante $y$ a la vez inquietante final de milenio. Obviamente son muchas $y$ muy complejas las materias susceptibles de análisis. Por ello, antes de nada, me gustaría aclarar el marco y los límites en los que se va a desenvolver este trabajo.

Como acertadamente señala A. Garrorena, el Derecho Constitucional es, sobre todo, el Derecho de la Constitución entendido como norma fundamental del Estado, es decir, como norma encargada de "constituir" la comunidad política, y no tanto el Derecho de la norma "constituida". La Constitución es la única que "crea" jurídicamente "a" la sociedad. Su carácter de norma que "constituye" a la sociedad le permite la posibilidad de recuperar la dimensión de totalidad que toda Constitución, en cuanto sistema fundamental de convivencia optado por un pueblo, implica y supone ${ }^{3}$. Por ello, en estas líneas voy a

3 Ángel Garrorena, "Cuatro tesis y un corolario sobre el Derecho Constitucional", en Revista Española de Derecho Constitucional, n. ${ }^{\circ} 51,1997$, pp. 40/44. 
centrar mi atención en esa valoración macroscópica del modelo constitucional entendido como respuesta global a la necesidad de establecer un suelo jurídico básico para nuestra vida en común, dejando así de un lado los, por otra parte necesarios, análisis microscópicos de la misma.

Ni los límites formales de este trabajo ni, por supuesto, mis propias limitaciones personales me permiten abordar, tan siquiera de forma aproximativa, los grandes retos a los que se enfrentan las Constituciones y el Derecho Constitucional en el momento actual. Por ello, a través de estas líneas tan sólo voy a limitarme a apuntar, a vuelapluma, algunas ideas en torno a la materia que nos ocupa. Tales ideas se centran, fundamentalmente, en torno a tres conceptos, a saber, el Estado, la soberanía y la Constitución.

\section{EL ESTADO EN LA ERA DE LA GLOBALIZACIÓN}

El actual orden jurídico-político se fundamenta en la división territorial del mundo en Estados soberanos, cada uno de los cuales ostenta un poder, una soberanía exclusiva, sobre un ámbito territorial determinado, expresado en una o varias líneas fronterizas de separación. Ello conlleva la necesidad de la defensa del ámbito territorial propio frente a las posibles agresiones exteriores. Por ello puede afirmarse que el orden político moderno se sustenta en la separación y el antagonismo entre Estados soberanos.

En ese orden político clásico, las fronteras tienen una importancia fundamental a la hora de definir el discurso de la soberania. No se trata sólo de unas fronteras físicas que delimitan y separan a un Estado soberano con respecto a otro $u$ otros. Junto a ellas se dan unas fronteras culturales que separan lo "mío" con respecto a lo de los "otros", $e$ incluso unas fronteras conceptuales que separan lo interno con respecto a lo internacional, la comunidad propia como orden frente a la anarquía. Dentro de las fronteras impuestas por el Estado soberano es posible la existencia de derechos $y$ obligaciones, orden, libertad, etc... Fuera de las mismas no existe orden ni comunidad 4 .

4 J. A. CAMILLERI Y J. FALK, The end of Sovereignty?, Edward Elgar Publishing, Aldershot, 1992, pp. 237/8. 
Tal como afirma H. Heller en su Teoría del Estado publicada en 1934, "el Estado se diferencia de todos los otros grupos territoriales de dominación por su carácter de unidad soberana de acción y decisión. El Estado está por encima de todas las demás unidades de poder que existen en su territorio". El Estado "es soberano únicamente porque puede dotar a su ordenación de una validez peculiar frente a todas las demás ordenaciones sociales". Esa soberanía le otorga "la capacidad, tanto jurídica como real, de decidir de manera definitiva y eficaz en todo conflicto que altere la unidad de cooperación social-territorial (...) y además, de imponer la decisión a todos". De este modo, el poder del Estado deviene, dentro de su territorio, en un "poder supremo, exclusivo, irresistible y sustantivo" lo cual le permite constituirse en "creador supremo de las normas" y tener "el monopolio del poder de coacción física legítima, la última ratio de todo poder"5.

En realidad, esa noción de soberanía exclusiva y hermética a la que alude Heller ha sido siempre más un mito que una realidad, un mito que ha servido más para legitimar la supresión de la competencia política, tanto en asuntos internos como internacionales, que para poder ejercer un poder real. Muy pocos Estados han ejercido en la prácti$\mathrm{ca}$, incluso en los momentos más álgidos del Estado nacional, una soberanía de estas características.

Siempre ha existido en el mundo contemporáneo una clara divergencia entre la división formal del mismo en Estados nacionales y la realidad social, económica, cultural, etc... subyacentes. Sin embargo, tal divergencia está alcanzando en el momento actual un grado y unas cotas difícilmente imaginables hace tan sólo unos años. Para comprobarlo basta con señalar algunos datos.

Frente a los 194 Estados que componen el mapa político mundial, la ONU cifra en 5.000 el número de grupos étnicos extendidos por el mundo ${ }^{6}$ y algunos autores calculan que actualmente existen en el mundo del orden de 10.000 sociedades o colectividades étnicas, lingüísticas, raciales, religiosas o con identidades de algún otro tipo; cuyo asentamiento poco o nada tienen que ver con el diseño de fronteras existente.

Los Estados son incapaces de abordar los problemas derivados de todo ese complejo mundo, y de hecho actúan tan sólo sobre una

5 Hermann Heller, Teoría del Estado, Fondo de Cultura Económica, México, 1985, pp. 255, $262,264$.

6 Informe del Relator especial Asjborn Eide. Documentos ONU E/CN.4/ Sub.2/1992/SR.32, p. 1, 1992. 
parte mínima del conjunto del sustrato del conocimiento humano. Así lo demuestra la existencia de alrededor de 18.000 organizaciones no gubernamentales que cubren la práctica totalidad de los asuntos humanos (científicos, culturales, humanitarios, económicos, políticos, etc...) relacionados con el bienestar de los seres humanos, bien a escala nacional o bien a escala global7. Sus limitaciones se muestran también en el ámbito estricto de la actividad política internacional. En el momento actual se contabilizan del orden de 2.000 organizaciones intergubernamentales cuya acción supone una limitación notoria de las posibilidades de actuación de los Estados.

La emergencia de toda esta nueva red de agencias, grupos, entidades, etc... no es el resultado de una moda o de la casualidad. Constituye una verdadera necesidad, un intento de respuesta a la consolidación de un progresivo sistema de intercambios internacionales derivado de la interdependencia compleja, el papel creciente de las empresas transnacionales ${ }^{8}$, y el descubrimiento y la difusión de nuevas tecnologías de producción, distribución y comunicación.

Este conjunto de nuevas realidades está horadando de forma extraordinaria los cimientos en los que hasta ahora se ha sustentado la teoría clásica del Estado. Basta con una simple mirada al mundo de 1998 y, particularmente, al funcionamiento efectivo de los Estados actuales para comprobar hasta qué punto han quedado obsoletas las teorías clásicas en torno al Estado.

La erosión del poder del Estado se manifiesta tanto a nivel interno como internacional. Así, en el ámbito interno, su actividad reguladora se ve sometida a restricciones cada vez más importantes y frecuentes. Bien por la complejidad intrínseca de la maquinaria estatal, o bien por la progresiva tendencia a estructurar el sistema de representación de intereses a través de organizaciones especializadas o corporaciones estructuradas en torno a criterios sectoriales o transectoriales, lo cierto es que el Estado se ve obligado cada vez con más frecuencia

7 Vid. Tatsuro Kunugl, Main actors of multilateral cooperation in the field of population and development, 1994, p. 1. Ejemplar reprografiado.

8 Resulta sumamente esclarecedor el contenido de un reciente informe de la UNCTAD relativo a las empresas transnacionales. En el mismo se indica que, en el momento actual, las empresas transnacionales, cuyo número se estima en torno a $\mathbf{4 0 . 0 0 0}$ empresas matrices más $\mathbf{2 5 0 . 0 0 0}$ filiales, constituyen el elemento dominante de la economía mundial, dado que las mismas acaparan las dos terceras partes del comercio mundial en bienes y servicios. Vid. Chakravarthi Raghavan, Third World Network Features, Ginebra, 24 de enero de 1996. 
a asumir complejas pautas de negociación'. Ello implica un importante retroceso de su poder y control jerárquico.

El resultado de todo ello lo constituye la progresiva desaparición de esos elementos que, de acuerdo con $\mathrm{H}$. Heller, han caracterizado tradicionalmente a los Estados: centralización territorial, monopolio efectivo del poder, o sujeción de todos los poderes seculares y religiosos al Estado. En su lugar se observa la aparición de procesos centrífugos en los que se produce una dispersión de competencias y poderes entre varios grupos o instituciones y tanto desde un punto de vista material como jurídico-formal. Ello provioca una difuminación creciente de la distinción clásica entre instituciones públicas y privadas, entre Estado y sociedad civil. En el momento actual, hasta los más sagrados intereses del Estado resultan sometidos a la contestación y a la restricción, $y$ hasta las fuerzas más "racionales y eficaces" del mercado quedan atemperadas por la negociación y la regulación.

Es, sin embargo, en el ámbito externo donde se manifiestan de forma más evidente las enormes limitaciones a las que actualmente se ve sometido el poder del Estado. Tal como ya he señalado antes, el acelerado proceso de interdependencia y transnacionalización que estamos viviendo actualmente en los órdenes tecnológico, científico, económico, cultural, humanitario, etc... están provocando un desfase absoluto entre el orden político y la realidad social. La mejor prueba de la velocidad e intensidad de este proceso la constituye el hecho de que, ni la capacidad política de acción de los viejos Estados nacionales, ni tampoco la de las recientes uniones de Estados, ni la de las conferencias internacionales que han logrado institucionalizarse, guardan ninguna proporción con el tipo de autorregulación que ofrecen los mercados global y mundialmente entrelazados entre síto.

La proliferación de organismos internacionales, tanto formales como informales, no emanados directamente de la "autoridad" de los Estados, o la marcada tendencia a una disminución de la efectividad de los gobiernos individualmente considerados, como consecuencia de la expansión de fuerzas e interacciones transnacionales, están haciendo que muchos de los ámbitos tradicionales de actuación del Estado (de-

9 Claus OfFE, "The Theory of the State in Search of Subject Matter: Observations on Current debates", en Modernity \& the State. Polity Press, Cambridge, pp. $64 / 5$. 1997, p.153.

10 Jürgen Habermas, Más allá del Estado nacional, Editorial Trotta, Madrid, 
fensa, etc...) ya no puedan ser llevados a cabo sin el recurso a formas internacionales de colaboración. Ello está obligando a los Estados a aumentar su nivel de integración política con otros Estados en órganos o instituciones supraestatales provocando, así, un extraordinario aumento de instituciones y organizaciones supranacionales ${ }^{11}$. Esa progresiva internacionalización resta posibilidades de acción autónoma al Estado y trae como consecuencia el que cada vez resulte más difícil la regulación de importantes procesos de decisión por parte de las Constituciones.

En el mundo actual el protagonismo de las relaciones internacionales no es ya exclusivo de los Estados, sino que corresponde a otros muchos entes, instituciones $u$ organizaciones (intergubernamentales, no gubernamentales, infraestatales $o$, incluso a entidades privadas de carácter mercantil, profesional, cultural, social, etc...). Estamos pasando de una rígida y hermética estatalización de las relaciones internacionales a una enriquecedora segmentación tanto territorial como funcional. Junto a la diplomacia, aparecen varias formas (global, interregional, transfronteriza, intermetropolitana, etc...) de paradiplomacia cuyo sujeto no es el Estado, y que son perfectamente compatibles con la diplomacia estatal ${ }^{12}$.

El resultado de todo ello es la quiebra profunda del principio de soberanía. Resulta difícil encontrar o identificar, actualmente, alguna soberanía única que lo sea realmente. Las fronteras son penetrables $y$ pierden su significado cuando actores no estatales pueden comunicarse a través del espacio. El Estado ha dejado de ser un actor unitario para convertirse en un marco más, no el único, en el que se negocian y resuelven las diferencias políticas. La acción colectiva cada vez se escapa más de la jurisdicción del Estado. Por ello, cada vez resulta más difícil mantener la idea del Estado como el garante, o al menos como el único garante, del "interés general".

Europa, y más concretamente Europa occidental, constituye, sin lugar a dudas, una de las zonas geográficas en las que se están manifestando de forma más evidente los cambios a los que acabo de aludir. A partir de 1945 quedó bastante claro que el orden político clásico ba-

11 David HeLd, Democracy and the Global Order, Polity Press, Cambridge, 1995, pp. 90/2.

12 Vid. I. D. Duchacek, pp. 13 ss., y P. Soldatos, pp. 35 ss., en Michelmann, H. J. y Soldatos, P. (eds.), Federalism and International Relations. The Role of Subnational Units, Clarendon Press, Oxford, 1990. 
sado en la división de Europa en Estados soberanos no resultaba ya adecuado para responder a los nuevos retos económicos, tecnológicos, militares, etc... En efecto, los Estados nacionales europeos están resultando afectados a lo largo de estos últimos años, en mayor o menor medida, por un doble fenómeno. El primero, exterior, derivado del proceso de interdependencia, cada vez más desarrollado, que se está produciendo en todos los ámbitos sociales, económicos, políticos, militares, etc..., y que se expresa en la aparición de estructuras, instituciones, organismos, etc... supranacionales. El segundo, interno, derivado de los cambios habidos en las relaciones de poder entre los diversos grupos e instituciones (entidades territoriales, corporaciones, grupos de presión, etc...).

Desde el punto de vista externo, la actividad de los Estados nacionales se ve condicionada de modo directo e importante por las tendencias transnacionalizadoras que ya han quedado citadas. Así, en lo económico se da una importante disminución de su capacidad para tomar decisiones autónomas como lo manifiesta no sólo la pérdida del poder regulatorio de su política financiera y monetaria, sino de otros muchos instrumentos económicos. Es evidente que la reciente implantación de la Unión Monetaria Europea mediante la creación del euro y la constitución del nuevo Banco Central Europeo, implica la pérdida de una parcela clave de la soberanía de los Estados nacionales.

Salvo acontecimientos excepcionales contradictorios con las tendencias que actualmente se manifiestan, no parece haber razones especiales para suponer que los Estados nacionales vayan a ser capaces de restaurar un equilibrio adecuado entre intercambios internos y externos, y ni tan siquiera, entre sus propias regiones. Por otra parte, su papel mediador entre las regiones económicas y las instancias de poder supranacionales, y su capacidad para ejercer un control adecuado y efectivo de la actuación de los oligopolios económicos se está reduciendo de forma notable. Cada vez resulta más frecuente hablar de procesos de desarrollo regional que superan el marco territorial estricto de los Estados.

Lo mismo ocurre en el ámbito político, donde se ha producido una progresiva participación en diversos organismos de cooperación (Consejo de Europa, OSCE, etc...) y sobre todo, una transferencia de competencias fundamentales por parte de los Estados a las instituciones comunes de la Unión Europea (UE). Por su parte el Acta Unica Europea de 1986 estableció, y el Tratado de Maastricht lo ha reforzado, un calendario para la eliminación de los obstáculos que impiden el libre movimiento de personas, bienes y servicios. Se está produciendo ya 
una eliminación de las fronteras internas que puede conducir, en breve plazo, a la implantación de una ciudadanía europea común. Ya se han unificado o europeizado determinados asuntos relativos a la Justicia y el orden público tales como asilo, inmigración, terrorismo, narcotráfico, delincuencia internacional, etc..., creándose incluso una Autoridad Policial europea. El reciente Tratado de Amsterdam no ha hecho sino ratificar e intensificar esa tendencia. Es evidente que todo esto supone una importante erosión de la soberanía propia de cada Estado.

Quizás donde la disminución o limitación de soberanía se manifiesta de modo particularmente dramático es en el ámbito de la política militar y de defensa. Un terreno que, como se sabe, constituye una de las razones más importantes, sino la fundamental que otorga al Estado nacional su propia razón de ser, la propia justificación histórica de su existencia. En el caso de Europa occidental, la Alianza Atlántica constituye, en cuanto organización supranacional bajo la dirección de un mando militar integrado en tiempo de paz, el caso más paradigmático de autodisolución de la razón de ser de los Estados nacionales. EI triple fundamento en que se asienta el Estado nacional: territorio, población y soberanía deja de tener sentido, ya que se desnacionalizan los ejércitos, a nivel exterior los Estados nacionales se convierten en regiones militares, y a nivel interior, el ejército deja de cumplir su objetivo histórico de la defensa de la integridad territorial del Estado nación.

La simbiosis entre revolución industrial y Estado nacional está dejando paso a una nueva simbiosis entre revolución tecnológica y un nuevo tipo de estructura política que todavía no somos capaces de definir. Es quizás en la propia UE donde, como señala P.C. Schmitter en un interesante estudio ${ }^{13}$, se manifiesta más claramente una nueva forma de gobierno emergente, totalmente diferente del Estado-nación clásico.

Así, por ejemplo, la UE carece de un lugar concreto de autoridad suprema. Es cierto que el Tribunal de Justicia de la Comunidad Europea (TJCE) puede dejar sin efecto leyes y decisiones específicas de los Estados miembros pero, en general, las decisiones constituyen el resultado de la negociación entre esos Estados. No existe un actor hegemónico que sea responsable en última instancia de tomar y aplicar decisiones vinculantes para todos, ni ninguna institución capaz de llevar

13 P. C. SCHMITTER, "La Comunidad europea como forma emergente de dominación política", en F. BEnedicto y F. ReInAREs (eds.), Las transformaciones de lo político, Alianza Editorial, Madrid, 1992, pp. 186 ss. 
a la práctica un elemento tan consustancial a todo Estado como es el ejercicio del monopolio de la violencia ${ }^{14}$.

Tampoco existe una estructura de cargos formalmente centralizada. La UE no posee una jerarquía de funciones cuyo vértice sea una autoridad central. La mayor parte de la división de funciones se rige por el principio horizontal de distribución de competencias, y no por el principio vertical de jerarquía. Se produce, de ese modo, una red formal e informal de interacciones horizontales y de continuas negociaciones entre los actores a diversos niveles, cada cual con su base de poder independiente.

A primera vista, la ausencia de un poder central jerárquicamente estructurado podría ser entendida como una fórmula de salvaguarda del poder de los Estados miembros. Sin embargo, la libertad de personas y mercancias, así como la unión de mercado y monetaria supone una ruptura con la rígida territorialidad en la que se fundamenta el sistema estatal europeo clásico. Ello trae como consecuencia un considerable desmantelamiento del poder estatal actual en Europa. Como puede verse, nos encontramos ante un nuevo tipo de Estado (más exactamente organización política, pues llamarla Estado resulta arriesgado, al menos si lo entendemos en su sentido clásico) todavía sin perfilar, pero con unas características y elementos básicos radicalmente diferentes de los conocidos hasta ahora ${ }^{15}$.

Esto no significa que los actuales Estados vayan a desaparecer necesariamente. El Estado nacional sigue manteniendo, al menos en principio, una cierta capacidad para determinar aspectos fundamentales de la actividad política tanto interna como internacional. Y lo sigue haciendo, entre otras cosas, porque el actual proceso de globalización no garantiza la configuración de una integración global entendida en el sentido de un solo orden mundial político o social unificado y homogéneo. Ello hace que el desplazamiento del Estado sea, y seguirá siendo, desigual e incompleto. La propia resistencia al proceso de globalización puede incluso justificar un reforzamiento temporal de la soberanía estatal en ciertos aspectos, al mismo tiempo que un debilitamiento en otros.

14 Por no tener, la UE no tiene siquiera un ejército propio, ni una estructura militar. Los asuntos militares se discuten en el marco de la OTAN, y de forma más específicamente europea, en el marco de la Unión Europea Occidental (UEO).

15 Vid. C. M. G. HimsworTH, "In a State no Longer: The end of Constitutionalism?", en Public Law, 1996, p. 643. 
Sea cual fuere el nuevo tipo de Estado emergente, lo cierto es que la progresiva integración de los Estados nacionales está originando ya importantes efectos en principios jurídico-políticos tan básicos $y$ fundamentales como el de la soberania, tal como ya ha quedado indicado anteriormente. El mito integrador del Estado nacional se ha definido, tradicionalmente, por tres dogmas clásicos de la soberanía como son la supremacía, la indivisibilidad, y la unidad del Estado. En aplicación de esos principios el Derecho y el Estado han ido permanentemente unidos. El Derecho en su sentido clásico, ha constituido siempre una emanación de la soberanía estatal. No se reconocía otro Derecho que el generado por el propio Estado, $y$ el Derecho internacional se aceptaba sólo en la medida en que el Estado lo legitimaba.

Con el proceso de unificación europea comienzan a resquebrajarse, o cuando menos debilitarse, esos principios tradicionales. Así, frente a la coincidencia entre un ente soberano y un territorio exclusivo donde se ejerce esa soberania, surge un sistema político multinacional, geográficamente abierto y en constante crecimiento. Frente a una soberanía única e indivisible se establece una soberanía compartida; junto a las leyes del Estado, han surgido normas comunitarias equiparables con aquéllas ${ }^{16}, y$ también, en su caso, leyes y normas regionales o autonómicas. A ello debe añadirse, como se verá luego, la creación de un Derecho transnacional derivado de los pactos o acuerdos jurídicamente válidos suscritos entre los entes interregionales, transfronterizos, etc...

La idea del Estado de Derecho, entendido como abstracción última del poder, sigue siendo perfectamente válida y continúa plenamente vigente, pero se trata ahora de un Estado de Derecho no asentado exclusivamente en el Estado-nación. La mutua interrelación entre Derecho comunitario, Derecho estatal, Derecho regional, y Derecho transnacional (por no hablar del Derecho internacional) hacen que el poder y la soberanía se compartan entre las diversas instancias y sujetos en función de los ámbitos materiales de competencia asignados a cada uno de ellos. El Estado nacional deja de tener la exclusividad en cuanto soporte de la legitimación y aplicación del Estado de Derecho, como lo muestra la presencia del Tribunal de Justicia de la Comunidad Europea o incluso el propio Tribunal Europeo de Derechos Humanos.

16 Se prevé que en un futuro cercano el 75 por ciento de la legislación nacional tendrá su origen directo o indirecto en la legislación comunitaria. Vid. Theo A. J. Toonen, "La Europa de las administraciones", en M. Arenillas y otros, La Europa de las Regiones, Universidad de Granada, 1994, p. 18. 


\section{EL LUGAR DE LA SOBERANÍA}

La soberanía constituye uno de los conceptos más complejos de la teoría del Estado y la Constitución, dado que en su contenido se mezclan aspectos morales, legales y políticos. Por ello, la idea de soberanía se manifiesta de formas muy diversas: como aspiración, como ideología, como mito, incluso como una pura ficción ${ }^{17}$.

Sea cual fuere su naturaleza real, lo cierto es que, desde el punto de vista formal, la concepción clásica de la soberanía se ha definido por tres grandes características: 1. Poder supremo, por encima de cualquier otro poder (religioso, económico, etc...). 2. Poder originario no derivado de ningún otro, en la medida en que le ha sido otorgado por el pueblo. 3. Poder independiente de cualquier otro. A partir de esos parámetros, la soberanía ha actuado como un factor de identidad fundamental del orden político clásico basado en la división del mundo en Estados nacionales independientes.

Es evidente que el proceso de transnacionalización ya aludido ha abierto profundas brechas en esa concepción formal clásica de la soberanía entendida como poder supremo, originario e independiente. Entre tales brechas cabe destacar la existente entre el ámbito formal (estatal-nacional) de la autoridad política y el sistema económico de producción, distribución y cambio estructurado a niveles no sólo estatales sino también globales y regionales. $O$ también la brecha entre la idea del Estado como actor independiente y el cada vez más amplio arraigo de organizaciones e instituciones internacionales o en su caso transnacionales. Así mismo, la brecha abierta entre la pertenencia a una comunidad política nacional manifestada en una ciudadanía, una titularidad de derechos, etc... y el desarrollo de un Derecho internacional, transnacional o europeo, por un lado, y un Derecho regional, por el otro. Tales órdenes jurídicos se aplican a sujetos individuales, organizaciones no gubernamentales y gobiernos e, incluso a un número cada vez más amplio de organizaciones intergubernamentales especializadas en materias muy concretas (servicios postales, transportes, ferrocarriles, trafico aéreo o marítimo, radiodifusión, etc...) dando así lugar a nuevos sistemas de regulación.

A la vista de estos datos, resulta difícilmente sostenible la defensa del principio de la soberanía, al menos en el sentido en que se ha entendido hasta ahora. En un mundo tan multilateralizado, ¿es posible

17 Richard Falk, On Human Governance, Polity Press, Cambridge, 1995, p. 87. 
mantener la idea de que los únicos depositarios de la autoridad soberana son los Estados? ¿Se puede seguir hablando todavía de soberanías indivisibles? ¿A qué otras instituciones hay que otorgarles, además o en lugar del Estado, el depósito de la soberanía? ¿Qué tipo de soberanía a unos y otros? Llegando más allá, ¿tiene sentido en el mundo actual mantener el propio concepto de soberanía? Son preguntas muy complejas a las que no es posible dar respuesta, ni tan siquiera especulativa, en un trabajo de estas características. Por ello, en las líneas que siguen tan sólo voy a limitarme a ofrecer, en voz alta, una serie de reflexiones provisionales en torno a este asunto.

Como recuerda F. Rubio Llorente, la noción de soberanía no es un concepto sociológico, sino una categoría normativa ${ }^{18}$. Es cierto que la soberanía hace referencia, en palabras de Kelsen, a la "cualidad de un orden normativo" 19 , pero no lo es menos que los cambios en la estructura de poder condicionan y limitan, y lo van a hacer mucho más en el futuro, tanto el contenido como la propia naturaleza de la soberanía. Este condicionamiento y limitación afecta, además, al doble ámbito en el que se expresa o manifiesta tal principio: el del poder constituido y el del propio poder constitúyente. La progresiva integración europea no sólo produce desplazamiento en el ordenamiento constitucional, sino que, en la medida en que se da una renuncia estatal a su exclusiva soberanía, la Constitución pierde una parte de su entidad original20.

Veamos primero la naturaleza de tales cambios en relación al poder constituido. Ya he señalado más arriba algunas de las importantes consecuencias derivadas del proceso de internacionalización, y particularmente en nuestro caso de europeización, en el ámbito del poder de los Estados. No voy a insistir en ello. Baste con recordar que son numerosas y muy importantes las materias ya transferidas por parte de los Estados en favor de la Unión Europea. La sola transferencia de tales materias ha provocado ya una alteración y limitación importante del poder soberano de los Estados los cuales, en gráfica expresión de J. Pérez Royo, han pasado de mantener una soberanía "limitable", a ejercer una soberanía realmente "limitada" 21 . Pues bien, una mirada al

18 Francisco RuBio LLORENTE, «El constitucionalismo de los Estados integrados de Europa", Revista Española de Derecho Constitucional, n. ${ }^{\circ} 48,1996$, p. 19.

19 Hans Kelsen, Principios de Derecho Internacional Público, Editorial El Ateneo, Buenos Aires, 1965, p. 376.

20 K. HeSSE, op. cit., p. 14. $148 / 9$.

21 Javier Pérez Royo, Las fuentes del derecho, Tecnos, Madrid, 1988, pp. 
contenido de los Tratados constitutivos europeos nos permite comprobar que las materias transferidas hasta el momento constituyen tan sólo una parte de los asuntos susceptibles de ser asumidos por la UE en un futuro próximo. Así, la UE puede asumir numerosas competencias en materias tan importantes como, por ejemplo, enseñanza (art. 126 TCCEE), cultura (art. 128 TCCEE), política sanitaria (art. 129 TCCEE), política social, política industrial, etc...

Sin embargo, el proceso de internacionalización y, en nuestro caso, europeización, no sólo está incidiendo en la distribución material de las diversas esferas de poder, sino que también ha comenzado a afectar, y de forma sustancial, al ámbito de los derechos y libertades. Una primera prueba de ello la constituye el artículo 10.2 de nuestra Constitución. Su doble condición de instrumento de interpretación y garantía de los derechos fundamentales, convierte a éste y a otros preceptos similares de las diversas Constituciones europeas en un elemento de integración de primera magnitud en orden a la consecución de un espacio común europeo de derechos y libertades.

En segundo lugar, no podemos olvidar la importante labor integradora de ciertos órganos creados al amparo de tratados suscritos por España y otros países europeos. Entre tales órganos cabe recordar, por su importancia, la labor del Tribunal Europeo de Derechos Humanos (TEDH) en su aplicación e interpretación del Convenio Europeo de Derechos Humanos. La aplicación del artículo 10.2 ha permitido que su abundante y rica jurisprudencia sea frecuentemente invocada y utilizada de hecho en el ámbito interno por los tribunales españoles, incluyendo el propio Tribunal Constitucional.

Asimismo conviene recordar, en el ámbito específico de la UE, el creciente protagonismo adquirido por el Tribunal de Justicia de las Comunidades Europeas (TJCE) no ya en las materias estrictamente comunitarias sino, en lo que aquí interesa, en la progresiva protección de los derechos fundamentales. EI TJCE viene manteniendo, sobre todo a partir de la sentencia Stauder/UIm (12.XI.1969), la tesis de que los derechos fundamentales, patrimonio jurídico de todos los Estados miembros, forman parte del ordenamiento jurídico comunitario como principios generales que deben respetarse.

Este conjunto de antecedentes no hacen sino confirmar la idea de una progresiva uniformización del valor de los derechos fundamentales en todo el ámbito jurídico de la Europa comunitaria, tanto a nivel de las instituciones comunitarias como de los propios Estados. Es cierto que la UE ha carecido, hasta ahora, de normas positivas comunes 
susceptibles de aplicación directa en el ámbito concreto de los derechos fundamentales. Pero todo apunta a que la creación de tales normas constituye una mera cuestión de tiempo22.

La realidad está exigiendo ya una aplicación a nivel europeo de ciertos derechos, tales como inmigración, asilo, libre circulación, etc... Veamos, a modo de ejemplo, el problema causado por las grandes migraciones que afectan a Europa en este momento. Los derechos fundamentales afectados por ese fenómeno (libre circulación, asilo, ciudadanía, etc...) sólo pueden ser satisfechos mediante una acción política $y$, en lo que aquí nos interesa, mediante una normativa jurídica, de carácter comunitario ${ }^{23}$. Resulta materialmente imposible el mantenimiento de una autonomía constitucional por parte de los Estados en este tipo de asuntos.

Esa progresiva regulación de los derechos fundamentales por parte de la UE y otras organizaciones internacionales viene determinada no sólo por la necesidad de universalizar esos derechos, sino también por la exigencia de otorgarles un contenido radicalmente distinto del hasta ahora vigente. Basta con lanzar una mirada a un derecho, y al mismo tiempo un concepto, tan fundamental para el derecho clásico, como es el de la ciudadanía para cerciorarnos de ello.

Tradicionalmente, los conceptos de ciudadanía y nacionalidad han ido estrechamente unidos en el marco de los Estados nacionales. En el derecho clásico, la condición de ciudadano de un Estado ha venido directamente ligada a la posesión de su nacionalidad. En el actual mundo de la complejidad ya no es posible mantener esta ligazón salvo que se quiera mantener lo que Ferrajoli ha calificado como "la mayor antinomia que aflige a los derechos fundamentales", a saber, la dico-

22 Algún autor ha señalado que el reciente Tratado de Amsterdam diseña en la práctica una verdadera "Carta de Comunitaria de Derechos Fundamentales" sustentada en un triple fundamento: el reconocimiento de un patrimonio común europeo; la consolidación de los derechos protegidos; y la instauración de la garantía de los derechos fundamentales. Vid. Frédéric SudRe, "La Communauté Européenne et les Droits Fondamentaux après le Traité d'Amsterdam", en La Semaine Juridique, n.os 1-2, 7 de enero de 1998, p. 10.

${ }_{23}$ La progresiva universalización de los derechos fundamentales no constituye un fenómeno exclusivo del área europea sino que se manifiesta, también aunque de forma menos intensa, a lo largo y ancho del mundo. Buena prueba de ello la constituye la creciente emergencia de numerosos instrumentos (instituciones, tratados, convenios o acuerdos tanto a escala universal como regional) reguladores de derechos y libertades. 
tomía entre derechos humanos y derechos fundamentales a partir de la categoria de ciudadania ${ }^{24}$.

El mantenimiento del concepto clásico de ciudadanía bien a nivel de cada Estado o bien a nivel europeo supone, como bien señala $\mathrm{E}$. Balibar, la necesidad de formular una regla de exclusión* que esté fundada por derecho y por principio ${ }^{25}$. Por ello, resulta imprescindible establecer un concepto de ciudadanía totalmente diferente y nuevo, un concepto que permita compatibilizar la titularidad y el ejercicio simultáneo de varias y diversas ciudadanías por parte de una misma persona. Pero para que ello suceda va a resultar necesario modificar de forma profunda muchos de los esquemas constitucionales clásicos e, incluso, la noción misma de orden constitucional.

La era de la globalización mundial está provocando no sólo el fenómeno de la transnacionalización económica, política, etc... sino también el de la propia transnacionalización humana a través de los flujos migratorios. En tal sentido, la idea de los Estados europeos asentados en sociedades perfectamente homogéneas se ha convertido en una mera ficción. La sociedad europea actual constituye, de hecho, un complejo y abigarrado melting-pot humano donde pugnan por convivir razas, religiones, lenguas, culturas, costumbres y tradiciones jurídicas extraordinariamente variadas. Estos cambios no sólo están afectando al ámbito político-institucional, sino a todos los ámbitos, social, cultural, familiar, etc..., de la vida del ser humano considerado tanto individual como colectivamente. Nos enfrentamos ante una profunda crisis del modelo estatal, tal como ha sido concebido hasta ahora. Junto a los conceptos de etnia, nacionalidad, ciudadanía, etc... cada vez nos resultan más comunes conceptos $y$ realidades nuevas tales como integración, asimilación, sincretismo, pluralismo, intercambio cultural, aculturación, etc...

Dada la estrecha conexión existente entre los conceptos de ciudadanía y nacionalidad, la existencia de cualquier identidad cultural diferente ha supuesto siempre un obstáculo, un cuerpo extraño, en el Estado nacional. Sin embargo, a partir de ahora, la diversidad de identidades culturales va a convertirse en una condicion indispensable

24 Luigi Ferrajol, Diritto e Ragione (Teoria generale del garantismo penale), Laterza, Bari, 1992, p. 950.

(*) El original en cursiva.

25 Etienne Balibar, "¿Es posible una ciudadania europea?», Revista de Filosofia Política, n. 4, Madrid, noviembre 1994, p. 27. 
para el desarrollo e institucionalización de la Europa unida. Los europeos nos enfrentamos a un espacio económico, político y cultural nuevo cada vez más vasto. Mantener y reforzar las identidades preexistentes ya no va a ser un obstáculo, sino una condición para la aceptación del nuevo espacio político ${ }^{26}$.

Vistas algunas de las consecuencias de la integración europea sobre la capacidad de actuación del Estado, sobre el poder constituido, conviene preguntarse ahora sobre los posibles efectos de tal integración sobre el propio poder constituyente.

El actual proceso de integración europea no ha logrado anular, todavía, la validez de la Constitución como norma creadora o constituyente del Estado. Es de todos sabido que la legitimidad de los Tratados europeos emana o se deriva de las Constituciones de los Estados miembros. Por lo tanto, mientras ${ }^{27}$ no se dé una Constitución europea, la soberanía seguirá radicando en las Constituciones de los diversos Estados.

Sin embargo, la UE se está configurando de forma cada vez más decisiva como una unidad efectiva desde el punto de vista político $y$ económico aunque no se halle regida por una Constitución común. Quiérase o no, la UE comienza a verse desde fuera como una unidad con la que se cuenta, y a la que se llama a concurrir en los escenarios políticos mundiales. De esta forma acrecienta su competencia, no ya por la autorización de los Estados miembros sino por razón de una situación política que le obliga a ejercerla ${ }^{28}$.

Por eso, la relación entre orden constitucional e integración europea deviene la cuestión decisiva de la situación constitucional en los

26 Dominique Wolton, La dernière utopie. Naissance de l'Europe Démocratique, Flammarion, París, 1993, pp. 15/16. El multilingüismo de Europa simboliza perfectamente algunas perplejidades actuales tales como el devenir de la identidad de los Estados nacionales y de las comunidades lingüísticas en el nuevo espacio político, o el devenir de la identidad del propio espacio político europeo. Como señala Habermas, de los procesos ciertamente conflictivos y dolorosos de tránsito a sociedades multiculturales surge una forma de integración social que apunta ya más allá del Estado nacional. El proceso de formación de naciones se repite a un nivel más abstracto: las estructuras de decisión política reciben ahora un nuevo substrato cultural. La forma multicultural de integración social incubada dentro del Estado nacional habrá de acreditarse más allá del mismo. (J. HaBermas, op. cit., pp. 180/1).

27 El original en cursiva. Etienne BALIBAR, «¿Es posible una ciudadanía europea?», Revista de Filosofía Política, n. ${ }^{\circ}$, noviembre 1994, p. 27.

${ }_{28}$ W. von SIMON/J. SCHWARZE, "Integración europea y Ley Fundamental", en Manual de Derecho Constitucional, op. cit., p. 20. 
próximos años. El Estado no puede llevar a cabo, por más tiempo, con plena autonomía, algunas de las funciones clásicas que a él se le asignaban. Ello trae como consecuencia la necesidad de dejar de actuar como una entidad independiente, autoconstituida, para integrarse en una colectividad más amplia, bajo una Constitución común, que comprenda a varios Estados.

Basta con analizar las últimas modificaciones constitucionales operadas en algunos de los Estados miembros de la UE para comprobar la progresiva integración constitucional de los mismos en el seno de la Unión. Tal como señala F. Rubio Llorente, el proceso de integración se apoyó inicialmente en cláusulas genéricas que habilitaban a los Estados para concertar limitaciones de soberanía. Esta técnica de habilitación genérica comienza a ser abandonada para ser sustituida por otras que articulan de manera distinta y más fuerte la vinculación del respectivo Estado con la Comunidad las cuales están provocando una "nacionalización" del Derecho comunitario. Es cierto que esta intensificación del proceso de integración se debate entre dos lógicas distintas, la lógica de la integración que supondría la prevalencia del Derecho europeo sobre los Derechos nacionales, y la lógica de la soberanía que fundamentaría en cada Constitucion nacional el poder de los órganos y la validez del Derecho' ${ }^{29}$.

En mi opinión, todo parece apuntar, salvo acontecimientos imprevisibles, a una prevalencia de la lógica de la integración sobre la lógica de la soberanía, y ello por varias razones.

La primera razón la constituye el manifiesto desequilibrio existente entre el grado de transnacionalización económico-social, e incluso política, y la permanencia de una vieja estructura jurídico-institucional. Tal como ha señalado Habermas, en el momento actual existe un riesgo real de capitulación del Estado de Derecho ante la complejidad social ${ }^{30}$. Los Estados y las instituciones internacionales cada vez van a tener más problemas para mantener su legitimidad si no son capaces de mantener una cierta autonomía con respecto a las fuerzas surgidas o, en su caso, protagonistas de la globalización, a la hora de atender a los problemas que se vienen planteando. En la conciencia de los ciudadanos europeos cada vez viene arraigando con más fuerza la idea o el sentimiento de que Tratados como el de Maastricht, o más recientemente el de Amsterdam, constituyen más un acto de despotismo ilus-

29 Vid. F. Rubio Llorente, op. cit., pp. 21 ss.

30 Jürgen Habermas, op. cit., p. 146. 
trado que una decisión democrática. Por ello, y al menos en lo que a la UE se refiere, tanto los cambios ya realizados como los que vayan a producirse en un futuro inmediato van a hacer imprescindible, en no poco tiempo, la necesidad de una Constitución europea común.

Una segunda razón viene determinada, como veremos a continuación, por el progresivo desequilibrio manifestado entre las atribuciones formales otorgadas a los Estados por sus respectivas Constituciones y la cada vez mayor limitación de sus competencias reales por parte de las organizaciones supraestatales $y$, particularmente en nuestro caso, la UE.

La superación de ese desequilibrio implica la necesidad de construir un mito-sentimiento europeo junto al mito-sentimiento constitucional de los Estados. La UE aparece hasta el momento como una formación racional, que no está por ahora en condiciones de apelar a un consenso de sentimientos que excluya la controversia ${ }^{31}$. Sin embargo, la sedimentación de ese sentimiento europeo va a resultar totalmente imprescindible en el futuro. Lo que mantiene unido un Estado abarca no sólo el proyecto común, lo conscientemente decidido, tal como lo encontramos en una Constitución, sino la existencia de certezas indefinidas, del espiritu, que traen causa de la historia común y de la experiencia interior. Pues bien, de la misma forma que cabe hablar de un mito del Estado, de un sentimiento constitucional, lo mismo cabe decir de la necesidad de un mito o un sentimiento europeo. Un sentimiento europeo que se forjará necesariamente en la diversidad social, cultural, lingüística, etc... dado que la identidad no puede tener el mismo estatus en una sociedad estatal-nacional cerrada que en una sociedad europea abierta.

\section{LA FUNCIÓN DE LA CONSTITUCIÓN Y DEL DERECHO CONSTITUCIONAL}

El sentimiento no es, sin embargo, en sí mismo suficiente. La sedimentación del sentimiento europeo exige la creación de una Constitución o un documento jurídico común a todos los ciudadanos europeos. Lo que une a los miembros de una sociedad definida por el pluralismo social, cultural y de valores es, primordialmente, la existen-

31 W. von Simon/J. Schwarze, op. cit., p. 25. 
cia de unos principios, unas reglas, unos procedimientos, es decir, un espacio público común o un orden jurídico-político.

Una vez constatada la imperiosa necesidad de configurar un ordenamiento jurídico europeo común, una Constitución ${ }^{32}$, se trata ahora de determinar, de una parte, qué tipo de relación debe establecerse entre las Constituciones de los Estados y la Constitución común y, de otra parte, qué características pueden definir a esa Constitución europea común.

Con respecto a la primera cuestión conviene aclarar cuanto antes que el actual proceso de globalización y, en nuestro caso, el previsible establecimiento de una Constitución europea no va a implicar la desaparición de las Constituciones estatales-nacionales actualmente vigentes. Y ello por dos motivos. En primer lugar, la soberanía de los Estados va a resultar imprescindible en el período de transición hasta la configuración definitiva de un ordenamiento jurídico-constitucional supraestatal. Los Estados van a seguir manteniendo muchas funciones tales como proteger físicamente a las personas, prestar servicios sociales básicos, facilitar a los ciudadanos el derecho a participar en la vida política e, incluso, representarlos a nivel internacional, dado que los individuos todavía seguimos siendo miembros de una comunidad internacional en la medida en que somos ciudadanos de un Estado. En segundo lugar, una vez estructurado ese ordenamiento, parece evidente que a una sociedad compleja y abierta como la actual, particularmente en el caso europeo, debe corresponderle también una soberanía $y$, por lo tanto, un ordenamiento jurídico-constitucional complejo $y$ abierto.

Por ello, no va a desaparecer la idea de soberania pero si va a resultar profundamente modificada en el futuro. La emergencia y proliferación de instituciones internacionales tanto de ámbito universal como regional, el desarrollo de organizaciones transnacionales, la aparición de nuevos derechos y obligaciones relacionados con la herencia común de la humanidad, la protección de ciertos derechos a nivel global, etc... están provocando la pérdida de la exclusividad del Estado como marco de ejercicio de la soberanía y, por tanto, dando lugar a la coexistencia, de forma simultánea, de diversas soberanias. Ello va a exigir a su vez, de hecho está exigiendo ya, el surgimiento y la coexis-

32 Tal necesidad ha sido manifestada ya de hecho por el propio TJCE al referirse, en varias ocasiones, a los tratados constitutivos como la Constitución de la CE. 
tencia de múltiples ciudadanías que permitan ejercer una diversidad de derechos políticos en las diferentes comunidades políticas a las cuales pertenecen esos ciudadanos.

El problema no se plantea, por lo tanto, en términos de sustitución o eliminación de las viejas soberanías por una nueva soberanía europea o de las vigentes Constituciones por una nueva Constitución, sino en términos de superposición entre ellas. He ahí el nudo gordiano de la cuestión que nos ocupa.

Conviene recordar en este punto, una vez más, la distinción entre titularidad y ejercicio de la soberanía. El hecho de que la titularidad de la soberania corresponda al pueblo no significa que sea el pueblo quien la ejerza necesariamente o, al menos, que la ejerza sin límites. El ejercicio concreto de esa soberanía vendrá determinado por la Constitución. Por ello, la Constitución, en cuanto norma o ley fundamental del ordenamiento jurídico, es también la depositaria de la idea de soberanía. En el Estado constitucional la soberanía nunca ha tenido un contenido absoluto ya que se halla limitada por los derechos individuales de los ciudadanos.

Pues bien, el actual proceso de internacionalización, y sobre todo de europeización, puede afectar de forma sustancial al concepto de soberanía tanto en su titularidad como en su ejercicio. En lo que respecta a la titularidad, queda fuera de toda duda la consideración del pueblo como sujeto titular de la soberanía. Lo contrario implicaría la desaparición de la democracia y el Estado de derecho. Dicho esto, se plantea, sin embargo, el problema de si cabe hablar de un pueblo entendido como unidad, única y exclusiva, de la que emana o se deriva la titularidad de la soberanía. Dicho de otro modo, debemos preguntarnos quién va a ser el pueblo del que una eventual Constitución europea futura reciba su legitimación, y en qué medida va a resultar posible la compatibilidad entre ese pueblo titular de la soberanía europea con la del pueblo titular de la soberanía en la que se asientan las respectivas Constituciones estatal-nacionales.

Lo mismo ocurre en lo referente al ejercicio de la soberanía. El declive de la concepción tradicional del Estado entendido como un ente soberano, nacional, relativamente hermético, para ser sustituido por un Estado o, si se quiere, un poder institucional nuevo, diferente, internacionalmente imbricado $y$ supranacionalmente integrado o vinculado provoca, obviamente, la pérdida de la primacía y de la entidad primordial que hasta ahora tenía la Constitución. 
La eventual aprobación de una Constitución europea nos sitúa ante una doble alternativa. $\mathrm{O}$ bien se sigue manteniendo la tesis clásica de una sola soberanía entendida en su triple sentido de poder supremo, originario e independiente, o bien optamos por la idea de que es posible una soberanía compartida. Si optamos por la primera alternativa, todavía nos queda por resolver el problema de si tal soberanía debe corresponder a la UE, o a los Estados nacionales o, en palabras de F. Rubio Llorente, si al final termina prevaleciendo la lógica de la integración o la lógica de la soberanía.

Frente a esta posición cabe una segunda alternativa consistente en optar por una soberanía compartida. Partiendo de la base de que resulta inevitable una Constitución europea y de que esa nueva soberanía europea no va a producir una extinción de la soberanía de los diversos Estados, sino una superposición de soberanías, entonces se plantea la cuestión de cuál va a ser la soberanía residual de los Estados y cuáles pueden ser los elementos de conflicto entre ambas soberanias.

Parece necesaria la configuración de una estructura compleja basada en la lógica o el principio de subsidiariedad que permita un reparto no sólo de competencias sino también de soberanía entre los diversos entes o instituciones. Un nuevo modelo, capaz de unir los elementos positivos de los modelos confederal y federal, en el que sea posible limitar el monopolio de los diferentes Estados, a nivel internacional o, en nuestro caso, europeo, como sujetos de derecho internacional, sin que esto signifique necesariamente acabar con el Estado ${ }^{33}$. Esta compartición de soberania es posible si aceptamos que la soberanía: “a) es suprema, pero en un sentido relativo, es decir, sólo respecto al ámbito de competencias que le atribuye la regla que la creó; b) limitada jurídicamente por las reglas que la constituyen en tal autoridad jurídica $(. .$.$) ; c) no es necesariamente única e indivisible. En un mismo$ orden jurídico puede haber distintas autoridades con competencias distintas y excluyentes" 34 .

Si los Estados están en crisis, si la justificación de la Constitución viene determinada por su condición de norma fundamental reguladora de las reglas básicas de funcionamiento de un Estado, salta a

33 Daniel Archibugi-David Held, Cosmopolitan Democracy. An Agenda for a New World Order, Polity Press, Cambridge, 1995, pp. 133/5.

34 José Luis Pérez Triviño, Los límites jurídicos del soberano, Tecnos, Madrid, 1998, p. 180. 
la vista de forma inmediata la necesidad de plantearnos con carácter general los posibles retos que se le plantean al constitucionalismo $y$, de forma particular, la cuestión de cuál puede ser el futuro de las Constituciones. En un momento como el actual en el que los Estados se hallan afectados por mutaciones de un calado tan extraordinario, ¿pueden seguir conservando las Constituciones el mismo sentido, el mismo significado que han mantenido hasta ahora? ¿Es absolutamente imprescindible que las Constituciones presupongan la existencia de Estados, al menos en el sentido clásico que ahora conocemos? ¿Puede haber Constituciones sin Estados? ¿Puede hablarse de Constituciones y de constitucionalismo más allá de los Estados? He aquí tan sólo una breve muestra de las muchas reflexiones que se le plantean al constitucionalismo y a los constitucionalistas en este final de milenio.

Es el ropaje del Estado el que da todo su sentido a la tradicional discusión tanto analítica como normativa de los principios $y$ valores que informan las normas de la Constitución. La propia idea del ejercicio del poder en el marco del orden constitucional, los principios de distribución o división del poder, las fórmulas a través de las cuales se controla el ejercicio del poder, el propio significado del Estado de Derecho, o la legitimidad del control de constitucionalidad, todos estos aspectos sólo resultan comprensibles en el contexto de un orden estatal35.

Resulta innegable que el declive del Estado nacional como única estructura jurídico-política a través de la cual se configura el Estado de derecho sitúa tanto a la idea de la Constitución como a la propia teoría constitucional en una encrucijada extraordinaria y de consecuencias bastante imprevisibles. Sin embargo, considero que tal cambio no tiene por qué significar necesariamente que el Derecho Constitucional vaya a disolverse totalmente hasta quedar reducido a una mera categoría histórica.

Como señala Hesse, con independencia de la forma que cobre en el futuro la Comunidad Europea, su existencia presupondrá siempre la de los Estados miembros y, con ellos, la de sus respectivas Constituciones. Y a su vez, por su parte, la futura UE solo podrá cumplir eficazmente con sus tareas si su ejecución es descentralizada y observa el principio de subsidiariedad ${ }^{36}$. El futuro del Derecho Constitucional de- 
penderá, por lo tanto, de su capacidad de adecuación a esa nueva estructura y tal adecuación implica el establecimiento de fórmulas de convivencia entre las Constituciones de los diversos Estados y la futura Constitución europea. Ambos niveles constitucionales -el europeo y los estatales - van a resultar imprescindibles.

Resulta del todo punto inviable seguir manteniendo la idea de las instituciones europeas como meros organismos delegados de la soberanía de cada Estado. El mantenimiento de tal situación ofrece el riesgo evidente de que el proceso de globalización o transnacionalización en el que nos hallamos inmersos provoque una pérdida real tanto de la efectividad como, incluso, de propia legitimidad del Derecho como método regulador de la convivencia de los seres humanos. Así está sucediendo ya, de forma alarmante, en el proceso de construcción europea. Por ahora, y dado que el grueso de la regulación de los derechos y libertades sigue siendo competencia de los Estados miembros, la pérdida de legitimidad del derecho viene afectando ¿tan sólo? a lo que, en términos convencionales podríamos calificar como la "parte orgánica" de la "Constitución" europea.

El hecho resulta en sí mismo lo suficientemente grave como para que la doctrina comience a plantearse de una vez por todas los límites, los condicionamientos e, incluso, la propia razón de ser de la teoría constitucional. Si esto es así ahora, ¿qué va a suceder en el momento en que la UE comience a asumir competencias de forma continuada y a tomar decisiones en materia de derechos y libertades? ¿Será posible asegurar la protección de los derechos fundamentales sin la existencia de una tabla comunitaria o europea de derechos, o al menos, sin una incorporación formal de la Convención Europea de Derechos Humanos al orden jurídico comunitario? ¿De qué garantías podrán disponer en ese momento los ciudadanos europeos, más allá de la protección del TJCE? ¿Qué instituciones u órganos serán capaces de mantener un control político a fin de hacer efectivas tales garantías? ¿Será posible seguir manteniendo la idea de que la legitimidad del poder de la UE se deriva o es un mero producto de la delegación de soberanía expresamente realizada por los diversos Estados?

Es preciso acabar con la idea clásica de que todo derecho emana necesariamente de una única fuente de poder, de una única soberanía. Frente a esta idea es necesario plantear la posibilidad de mantener una visión más amplia o más difusa del derecho. Como señala MacCormick, se trata de construir un concepto de derecho que permita la posibilidad de solapamientos e interacciones entre diversos 
sistemas legales, sin que tenga que suponer ello, necesariamente, la subordinación o jerarquización entre ellos, o con respecto a terceros sistemas ${ }^{37}$.

Frente a la concepción monista, kelseniana, de un sistema jurídico entendido como un todo unitario, parece más adecuada una visión pluralista capaz de mantener una compatibilidad entre sistemas que se solapan e interactúan mutuamente. Como bien señala Hart, hay muchas formas y grados posibles de dependencia e independencia. Si bien la palabra Estado introduce o sugiere alguna medida de autonomía, ello no supone necesariamente sostener que esa autonomía tiene que ser ilimitada o que sólo puede estar limitada por cierto tipo de obligación ${ }^{38}$. En la Europa contemporánea, y particularmente en ese orden jurídico complejo que constituye la UE, ya no resulta necesario aquel concepto clásico de soberania que implicaba necesariamente la configuración de relaciones jerárquicas de supra o subordinación.

La construcción de ese orden jurídico complejo hará posible la coexistencia entre un derecho comunitario $y$ un derecho interno basados en una relación de equiordenación y no en una relación de supra o subordinación. Pero, además, debe convertirse en una fórmula imprescindible a la hora de reestructurar sobre nuevas bases, más adecuadas a la realidad política de nuestro tiempo, la relación entre derecho interno y derecho internacional. La distinción actualmente vigente entre derecho interno y derecho internacional se halla sustentada en la concepción kelseniana del derecho y parte de la afirmación de que concebir una soberanía externa junto a una soberanía interna es, en cualquier caso, erróneo: "una y otra no pueden ser separadas y si un Estado está sometido a otro Estado respecto a sus relaciones internacionales no es 'soberano', aunque sus poderes legislativo, administrativo y judicial no estén de otra manera restringidos" 39.

La concepción clásica de la soberanía establece una distinción tajante entre derecho interno y derecho internacional. Mientras que el ordenamiento jurídico interno implica un conjunto de normas perfectamente estructuradas en torno a los principios de unidad y globalidad, el ordenamiento jurídico internacional se nos presenta como una reali-

37 Neil MACCORMick, "Beyond the Sovereign State", The Modern Law Review, vol. 56-1, 1993, Oxford, pp. 8 ss.

${ }_{38}$ H. L. A. HART, El Concepto de Derecho, Abeledo-Perrot, Buenos Aires, 1995, pp. 274/5.

39 H. KELSEN, op. cit., pp. 97/98. 
dad compuesta por un pluralidad de formas y de órdenes parciales, una realidad caracterizada por un exceso de órdenes, de estructuras evanescentes. De esta forma, el ordenamiento jurídico internacional se ha configurado siempre como un "desorden" entendido no en un sentido negativo de falta de orden sino en el sentido positivo de redundancia o exceso de órdenes ${ }^{40}$.

Ya no resulta posible seguir manteniendo esta idea en el momento actual. Los cambios producidos como consecuencia del proceso de transnacionalización o globalización actuales están provocando que ese "desorden" positivo derive, en la práctica, en una auténtica falta de orden, en una verdera anarquía internacional.

Los nuevos tiempos requieren reglas también nuevas. Como senala M. Bedjaoui en su análisis del futuro del Tribunal Internacional de Justicia de La Haya, es necesario configurar ciertas categorias de conflictos denominados internos pero con una repercusión internacional cierta que hace más necesaria que nunca una redefinición y un desarrollo del derecho internacional en los ámbitos más importantes para la estabilidad de la sociedad internacional. Pero para que tal reconfiguración resulte posible hay que tener en cuenta las mutaciones internas y externas de los Estados y reconocer el lugar cada vez más amplio ocupado por las organizaciones internacionales ${ }^{41}$.

Afortunadamente, en el derecho internacional contemporáneo se va afianzando cada vez con más fuerza la idea de que la soberanía de los Estados no puede servir de escudo inexpugnable frente a graves violaciones de los derechos humanos. Ya no es posible obviar responsabilidades amparándose en el eufemismo del asunto interno. A estas alturas no tiene sentido el mantenimiento de una separación tan rígida entre lo interno y lo externo. Por eso, cualquier actitud que haga prevalecer el principio de la soberanía nacional sobre el respeto a la dignidad humana resulta radicalmente contraria a los más elementales principios de justicia42.

Esta progresiva difuminación entre el derecho interno y el derecho internacional sitúa a los juristas en la perspectiva de un nuevo ho-

40 Vittorio FrosinI, "Kelsen y las interpretaciones de la soberania», en $R e$ vista Española de Derecho Constitucional, n. ${ }^{\circ}$ 31, 1991, p. 73.

41 Mohammed BEDJAOUI, Nuevo orden mundial y control de legalidad de los actos del Consejo de Seguridad, IVAP, Oñati, 1995, pp. 124/5.

42 Antonio CASSESE, Violence and Law in the Modern Age, Polity Press, Cambridge, 1986, p. 170. 
rizonte cual es el de la necesidad de asumir la elaboración progresiva de un constitucionalismo mundial ${ }^{43}$. Un constitucionalismo regulador de un ordenamiento jurídico complejo en el que sea posible la convivencia de órdenes jurídicos diversos no sustentada, necesariamente, en relaciones jerárquicas de supra o subordinación, sino en criterios de compartición, coordinación y subsidiariedad. Ese es, en definitiva, el gran reto del constitucionalismo ante el siglo XXI.

43 Luigi Ferrajoll, "La conquista de América y la doctrina de la soberanía exterior de los estados", en R. BERGalLI-E. RESTA, Soberanía: Un principio que se derrumba, Paidós, Barcelona, 1996, p. 175. 